\title{
Un-Dutching the Delta Approach: network management and policy translation for effective policy transfer
}

Ellen Minkman, Arwin van Buuren and Victor Bekkers

\section{(2) OpenEdition Journals}

Electronic version

URL: https://journals.openedition.org/irpp/2174

DOI: $10.4000 /$ irpp. 2174

ISSN: 2706-6274

\section{Publisher}

International Public Policy Association

\section{Printed version}

Date of publication: 30 October 2021

Number of pages: 172-193

ISSN: 2679-3873

\section{Electronic reference}

Ellen Minkman, Arwin van Buuren and Victor Bekkers, "Un-Dutching the Delta Approach: network management and policy translation for effective policy transfer", International Review of Public Policy [Online], 3:2 | 2021, Online since 01 August 2021, connection on 16 December 2021. URL: http:// journals.openedition.org/irpp/2174 ; DOI: https://doi.org/10.4000/irpp.2174

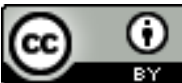

International Review of Public Policy is licensed under a Creative Commons Attribution 4.0 International. 


\section{Un-Dutching the Delta Approach: network management and policy translation for effective policy transfer}

\section{Ellen Minkman}

Technische Universiteit Delft, The Netherlands

\section{Arwin van Buuren}

Erasmus University Rotterdam, The Netherlands

\section{Victor Bekkers}

Erasmus University Rotterdam, The Netherlands

\section{Abstract}

This study identifies network management as a facilitator of effective policy transfer. We reconstruct the unconventional collaboration between Dutch private-sector experts and national governments of Vietnam and Bangladesh to develop multi-sectoral, long-term strategies ('delta plans'). We identify the network management strategies used by the Dutch actors and use these to explain how problem perceptions of state and non-state actors were aligned in order to define solution pathways. Based on these cases, we argue that network analysis is a tool for policy transfer studies. This paper further concludes that the 'soft' nature of the transferred policy (in the form of principles, norms and ideas) increased its transferability, as being ambiguous and abstract left room for interpretation and translation to the local context.

\section{Keywords}

policy transfer, policy translation, network management, adaptive delta management

\footnotetext{
We would like to thank our interns Alex López Alberola, Lucy van Eck and Nathan Kars for the background research as well as Nguyen Hong Quan, Luu Tang and Dung Duc Tran from VNU-WACC for their collaboration in Vietnam. We also owe a lot to Jaap de Heer, William Oliemans and Giasuddin Ahmed Choudhury for introducing us to their network in Bangladesh. Naturally, this research would not have been possible without our respondents.
}

The author(s) disclose receipt of the following financial support for the research, authorship, and/or publication of this article: this work was supported by a research project contribution Deltares [no grant number available] and a Ph.D. project grant from the Institute for Housing and Urban Development Studies (IHS) [no grant number available]. 


\section{Introducing network analysis to policy transfer studies}

While public policy studies traditionally focus on activities by state actors, state actors and non-state actors congregate and collaborate in networks to transfer policy ideas from one place to the other, particularly in epistemic communities and transnational policy networks (Benson \& Jordan, 2011; Moloney \& Stone, 2019). In general, policy transfer requires collaboration between multiple actors from different countries and a network of different actors, all with unique resources (Klijn et al., 2010; Koffijberg et al., 2012). There are indications that both the composition (James \& Lodge, 2003) and management (Vinke-de Kruijf, 2013) of policy transfer networks affect the effectiveness of the transfer. This article seeks to deepen our understanding of the networked character of processes of policy transfer and focuses upon the network management strategies deployed by transfer agents to facilitate policy translation.

Although networks have self-organizing capabilities, their active management is of crucial importance to reach collective outcomes and to realize goal alignment and interaction, (Klijn et al., 2010; Warsen et al., 2018). Network management in policy transfer is hereby understood as an attempt to guide the transfer and reception of travelling ideas in policy formulation networks that are formed in the receiving context. To date, the relationship between network management and policy transfer has hardly been analyzed. The objective of this study is therefore to increase our understanding of the role of network management in policy transfer, and in particular the effectiveness of this transfer. To this end, we will attempt to respond to the following research question: "How do the network management strategies applied by policy transfer senders help explain the (in)effectiveness of policy transfer in the case of transfer of the Dutch Delta Approach (DDA) to Bangladesh and Vietnam?" The term 'effective' is preferred over 'successful'. Indeed, the latter may bear normative connotations while the intention of this research is to assess the role of network management as a tool for effective policy transfer (which is understood in this article as accessing the policy-making network and translating ideas to fit the receiving context) without evaluating the suitability of the ideas transferred.

This question will be answered through a qualitative, comparative case study on the transfer of the DDA to Vietnam and Bangladesh. As will be explained in detail in section 3.1, these are considered exemplary cases of effective policy transfer, as both countries adopted a delta strategy that was inspired by the Dutch example. Moreover, these transfers can be compared because of the similarities in scope of the transfer. A longitudinal comparison of the two most-similar cases allows for an in-depth understanding of the complex dynamics of the transfer process, the strategic actions of actors and the interdependencies between them. In this study, we will create - based on network theory - an analytical framework of the network management strategies that guide the collection and analysis of empirical data. As the Dutch government has no jurisdiction in both Bangladesh and Vietnam, the transfer was based on bilateral cooperation, which makes both cases suitable for a study on the role of network management in (effective) policy transfer. Because of the similarities between the cases regarding scope, process and outcome, we are able to isolate the deployed network management strategy as a distinguishing variable between the cases. After presenting the theoretical foundation and methodology in section 2 and 3, the case reconstructions will be presented in section 4 . Section 5 will show how the network brought together actors with political power. It will also discuss the network management strategies deployed by the Dutch actors and how these led to the convergence of domestic and foreign actors. Lastly, we conclude that the network management strategies used most frequently to facilitate effective policy transfer involved connecting and exploring content. We highlight the relevance of using network analysis, i.e., analyzing the policy transfer network and network management strategies deployed by transfer agents, to study policy transfer. 


\section{Theoretical framework: the role of networks and translation in policy transfer}

Policy formulation networks are dynamic and complex multi-actor arrangements (Yoo \& Kim, 2012, p. 819) in which actors are interdependent on each other's resources to formulate a joint approach (Klijn \& Koppenjan, 2016). In such "a complex web of state and non-state actors" (Stone, 2012, p. 495), policy transfer adds an extra layer to this. It refers to the process whereby knowledge about policies from one place is used in the policy formulation process elsewhere (Dolowitz \& Marsh, 1996; Evans \& Davies, 1999). Transfer is seen as a multi-directed translation process in which multiple actors, particularly specialists and administrators, interact in order to shape the content and process (Mcguire \& Agranoff, 2011).

Policy transfer, however, is often rushed and actors overlook the fact that learning to collaborate takes time (Johnston, 2005). Effective policy transfer requires the translation of ideas so that they fit into other contexts, and the generating of support from actors who can induce policy change, either by directly adopting ideas into policy or persuading state actors to do so (Béland \& Cox, 2016; Klijn \& Koppenjan, 2016). The need for policy translation emerges because policy solutions are developed in a certain context, which limits the range of possible applications elsewhere (De Jong \& Bao, 2007). Receiving actors fit ideas in their frames of reference to minimize the need for change or the impact on existing policies. Policy ideas thus change shape when travelling between countries, a process referred to as policy mobility or policy transfer (Mukhtarov et al., 2016; Peck \& Theodore, 2010). In this paper, we use the term translation (Dolowitz, 2017; Stone, 2012). Transferred policies are not always institutionalized. In particular, 'soft' transfer objects - consisting of principles, norms and planning ideas - are infrequently institutionalized; they also depend more on the translation of ideas through close interaction between agents than on hard objects such as programs or techniques (Khirfan et al., 2013; Stone, 2012). Moreover, political power, dependency relationships and language affect how actors interpret, assign meaning and modify travelling ideas (Mukhtarov \& Daniell, 2016; Stone, 2016). A recent study showed the importance of analyzing the narratives used by the actors involved at the sending and receiving end, as these narratives play an important role in shaping the policy transfer process (Soremi, 2019). Policy transfer entails social construction within an actor-network where ideas are framed and translated so that they fit into the receiving context, and where the outcome depends on which actors are involved and how they interact.

\section{Network management in policy transfer}

A governance structure for policymaking that is based on networks is referred to as network governance. Such governance relies on relationships and strives to achieve consensus-driven goals through negotiated interactions between public, semi-public and private actors in temporary configurations around a specific policy issue (Mcguire \& Agranoff, 2011; Sørensen \& Torfing, 2005; Yoo \& Kim, 2012). It could facilitate the pro-active identification of policy issues and solutions, the gathering and negotiation of knowledge for decision making and conflict management, and the mobilization of support for implementing policy measures (Sørensen \& Torfing, 2005, pp. 197-198). Decision making through networks is thus complex and actors may attempt to influence the network in which they participate to optimize its functioning. Such network management is especially essential for organizing complex governance processes that require innovative solutions (Bekkers \& Tummers, 2018; Warsen et al., 2018), including policy transfer and translation (Benson \& Jordan, 2011; Stone, 2012). 
The existing literature on network management helps shed light on how network management strategies are deployed in policy transfer and how these strategies affect the translation of transferred ideas. Network management may be targeted at the institutional design of the network for policymaking or at the policymaking process within that network (Klijn et al., 2010). We will concentrate on the latter, given our interest in the role of network management in policy transfer. In theory there is an infinite number of strategies that actors in the network can deploy and an almost equally large number of categorizations of network management strategies. These categorizations all concern the policy content, the actors in the network, how these actors interact and how the process is organized (Warsen et al. 2018). As such, we adopt the framework by Klijn, Edelenbos and Steijn (2010) to classify network management strategies observed in policy transfer. Table 1 provides an overview of the four categories of strategies the authors distinguish.

The composition of networks for policy formulation following policy transfer may be unplanned or, on the contrary, carefully thought out. Although transfer networks may emerge ad hoc (Evans \& Davies, 1999), Evans and Barakat (2012) observed that such networks are often deliberately composed of elite decision-makers, including policy entrepreneurs, key bureaucrats, politicians and privileged groups. The network composition is thus important, as it may affect how ideas spread and ultimately, whether they are adopted (James \& Lodge, 2003). Powerful, key actors in the policy process should embrace and promote the idea before the policy course is changed (Béland \& Cox, 2016). A first category thus concerns strategies to connect with certain actors. Connection strategies may be used to identify and involve certain actors based on their relationship to a particular policy problem, their resources and their interests.

A second group of strategies relates to actors' interests and problem perceptions as well as to the exploration of potential solutions. Policy networks consist of a diverse set of actors, with equally diverse perceptions of the problem and/or the solution to that problem. This results in substantive complexity (Klijn \& Koppenjan, 2016). Also, tension may emerge because of the ambitions of a transfer agent's own organization and the need to negotiate (Johnston, 2005). Actors in the network may then deploy various content-based strategies (such as joint fact finding and intertwining goals) to deal with these varying perspectives (Klijn \& Koppenjan, 2016) and may attempt to frame the transferred policy as a solution to a pressing policy problem in the receiving context (Béland \& Cox, 2016).

The third type of strategy relates to process agreements. Bringing together actors with diverging objectives, interests and resources in the policy network contributes to the complexity of interactions. Transferring actors need to access another institutional network, with which they are probably unfamiliar. Institutional complexity arises when the rules of this policymaking game are unclear or conflicting or when actors do not trust each other (Klijn \& Koppenjan, 2016). Process arrangement strategies address this, for example by clarifying the rules of interaction.

Finally, these interactions take place in different policy making arenas, which are not accessible to all actors at the same time. For example, the transferring agent will not have access to political debates in the receiving context. Arranging strategies concern the creation of new institutional arrangements in which (part of) the network interacts. An example of such arrangements are projects, funded by international organizations, which serve as policy transfer channels (Sezen, 2011). 
Table 1. Four different strategy types and the operationalization in this study

\begin{tabular}{|c|c|}
\hline Type & $\begin{array}{l}\text { Operationalization (based on Klijn et al., 2010): included when they } \\
\text { concern... }\end{array}$ \\
\hline Connecting & $\begin{array}{l}\text { - Engaging new actors in the network } \\
\text { - Disengaging existing actors } \\
\text { - Reasons to co-operate } \\
\text { - Formation of a coalition } \\
\text { - Different interaction patterns than before }\end{array}$ \\
\hline $\begin{array}{l}\text { Exploring } \\
\text { content }\end{array}$ & $\begin{array}{l}\text { - Aligning goals of different actors in the network } \\
\text { - Joint fact finding } \\
\text { - Creating alternative solutions } \\
\text { - Explicating perceptions of problem and/or solution } \\
\text { - Activities to influence other actor's perceptions }\end{array}$ \\
\hline $\begin{array}{l}\text { Process } \\
\text { agreements }\end{array}$ & $\begin{array}{l}\text { - Who can enter the process in which way } \\
\text { - (implicit) rules of dealing with conflict } \\
\text { - Rules that specify the decision-making process } \\
\text { - Rules that specify access to information }\end{array}$ \\
\hline Arranging & $\begin{array}{l}\text { - new organizational arrangements for the purpose of policymaking in this network } \\
\text { - funding arrangements }\end{array}$ \\
\hline
\end{tabular}

Source: Based on Klijn et al., 2010, p. 1069

\section{Effective policy transfer: translation and network management}

The question of 'successful' policy transfer has generated much debate. Some argue that policy transfer success simply implies the adoption of policy ideas, while others attest that success should be measured in terms of achieving (political) objectives (see e.g. Dunlop, 2017; Marsh \& Sharman, 2009; Rusu \& Loblova, 2019; Stone, 2016). Similarly, the effectiveness of network management can be defined as the extent to which the network achieves its goal (Mcguire \& Agranoff, 2011) and whether actors in the network are satisfied with the results (Klijn \& Koppenjan, 2016). Peters et al. (2017) further suggest that multi-sector networks in particular benefit from active coordination. In this article, we take a different starting point, namely that policy transfer takes place in a context where multiple actors are able to translate the transferred ideas in different ways. Effective policy transfer thus entails that (a) transferring actors are granted or obtain access to a suitable network; (b) this network is able to translate the policy to fit the receiving context and (c) this translated policy is adopted by policy makers in the receiving context. Overall, our argument is that effective network management facilitates effective policy translation.

\section{Method}

This study is, to the best of our knowledge, among the first to link network management to effective policy transfer. We therefore opted for a qualitative and comparative case study of the transfer of the DDA to Vietnam and Bangladesh. Specifically, we mapped the network strategies deployed by the transferring Dutch actors and analyzed how these contributed to effective policy transfer. 


\section{Transfer of the Dutch Delta Approach}

The Netherlands has a long-standing international reputation for water management and has embraced the novel concept of Adaptive Delta Management (ADM), which crystalized in the Delta Program. This program combines 'hard' infrastructure measures with 'soft' governance (Wesselink, 2016). The Dutch government considers that this approach may be effective in other delta-countries and has actively diffused the set of underlying values and measures such as the DDA, which serves as the transfer object in this study. For an elaborate description, see Büscher (2019) and Minkman and Van Buuren (2019). However, as Zevenbergen et al. already noted, "ADM is not an approach that can be transferred easily from one country to another as it demands a fundamental change in institutional capacity at multiple levels (...) and, hence, depends on the local socio-economic characteristics, culture and governance." (2018, p. 299) The DDA is therefore an exemplary case for a policy transfer whereby network management is needed.

Knowledge about the Dutch approach to delta management has been transferred to various countries in Africa, Asia, South- and North-America and within Europe. The Dutch government has focused on urban deltas, selecting a number of such deltas for multiyear cooperation $^{1}$. As policy transfer requires time to be effective (see e.g. Dussauge-Laguna, 2012), we focus on these 'delta countries'. While the exact scope - and thus the transferred policy ideas - varies from case to case, the attempts to transfer the DDA to Vietnam and Bangladesh show many similarities. Both were initiated around the same time (2011 and 2014) and under the name of development cooperation. Moreover, the scopes of both transfers were similar, namely formulating delta plans for a transition of planning and governance to future-proof delta management in, respectively, the Ganges-Brahmaputra river in Bangladesh and Mekong river delta in Vietnam. Of all the attempts to transfer the DDA, these were the scopes most similar to the newest pièce de resistance in Dutch water management: the abovementioned Delta Program. Finally, transfer outcomes were similar because the Dutch government considered both to be success stories. As such, we chose to study the transfer of the DDA to Bangladesh and Vietnam.

A qualitative case study allows us to observe contextual interactions and mechanisms and to analyze these dynamics over time. The selected cases had the most similar outcomes. As such, we compared the Vietnamese Mekong Delta Plan (MDP) and Bangladesh Delta Plan 2100 (BDP 2100) following Mill's Method of Agreement (Levi-faur, 2005). As outlined above, these cases were both in Asia, they were closest in scope among the various transfer attempts of the DDA and they resulted in the adoption of the translated policy. One advantage of this approach is that it reduces variance in the dependent (effective transfer) and independent variable (network management) because the other factors that affect transfer are different between the cases. Although policy transfer studies initially concentrated on Western countries, Zhang and $\mathrm{Yu}$ (2019) underscored that policy transfer is a suitable analytical framework to study administrative reforms in transition countries such as Bangladesh and Vietnam.

\section{Literature review and interviews}

Policy transfer requires a longitudinal study, because a transfer is not a single event but a sequence of 'stages' and loops (iterations) in which knowledge is transferred, utilized and adopted (Dolowitz, 2017; Dussauge-Laguna, 2012). Both the cases we selected have been extensively studied and are well-documented. We reviewed existing studies (see Appendix E for an overview) to create case descriptions, formulate preliminary answers to the research question

1 - Over time, some countries have been included or excluded from the list. In 2020 the delta countries were: Indonesia, Bangladesh, Mozambique, Vietnam, Egypt and Myanmar. 
and identify information lacunas to feed semi-structured interviews. These interviews were conducted between 2016 and 2019, with a peak between April and June 2019 when the first author spent two months in Bangladesh and Vietnam. All interviews were conducted by the first author in Dutch or English, expect for six interviews in Dutch conducted by a research assistant and six interviews in Vietnamese co-conducted with Vietnamese researchers. In order to incorporate different perspectives that were indirectly involved - and often more critical -, stakeholders were interviewed, including NGOs and researchers. An overview of the respondents can be found in Table 2. As these interviews were collected as part of a larger research project, respondent identification numbers run to 103 and thus exceed the number of interviews used for this particular study.

Interviews were transcribed and coded in Atlas.ti using the four network management strategies as primary codes. In addition, other key concepts from the theoretical framework and a code for context were added. Creating images of the contexts of the cases is important as context affects how the policy will be translated and shape the policy formulation process. Actor, process and network analyses were then performed (for a detailed method description, please consult Klijn \& Koppenjan, 2016, pp. 259-288). The strategies identified were subsequently clustered using the framework developed by Klijn, Steijn and Edelenbos (2010). Although all actors may deploy network management strategies, this study focuses on Dutch actors. This will increase our understanding of whether and how senders apply network management to achieve effective policy transfer.

Table 2. Overview of interviews conducted in both cases between 2016 and 2019.

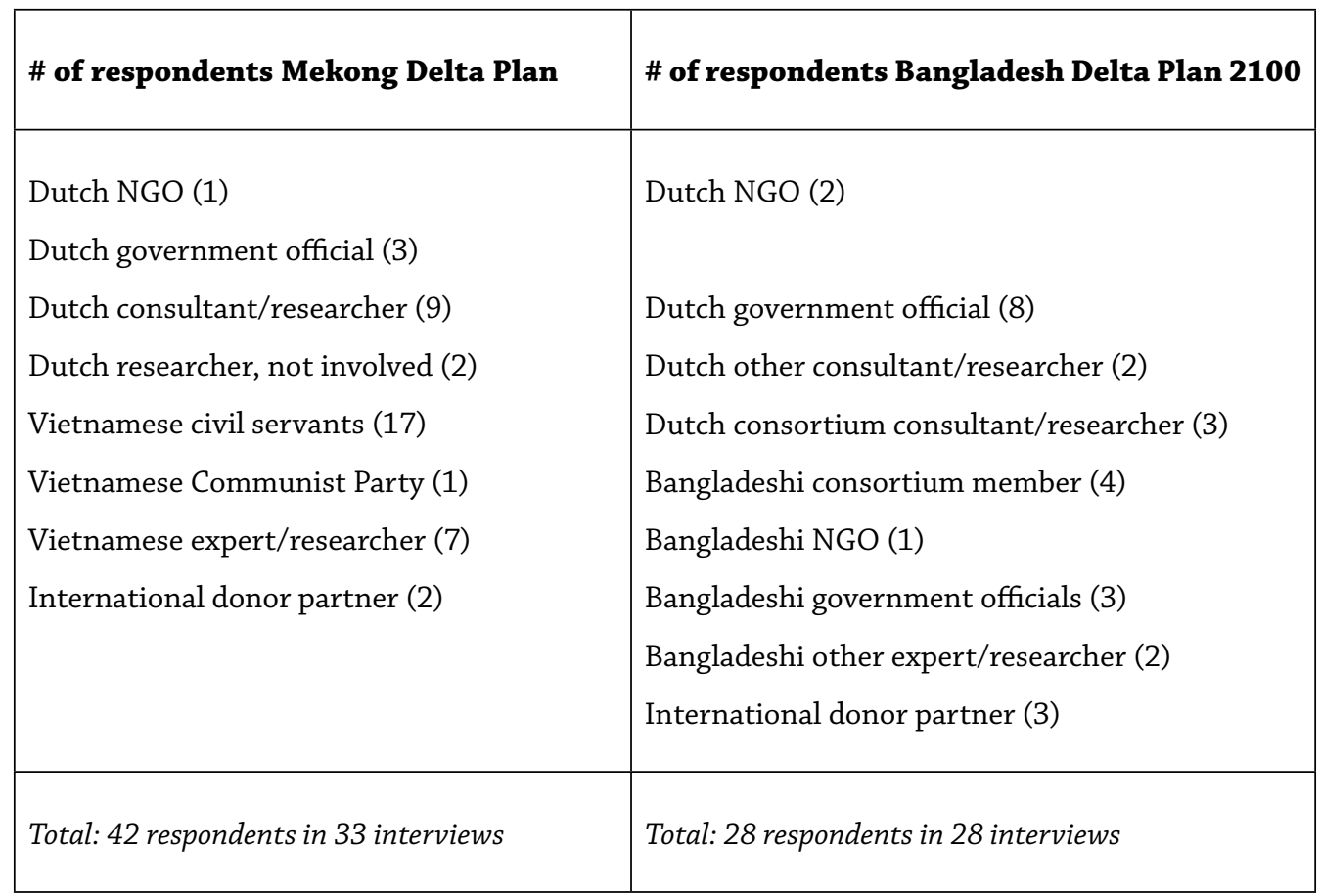

Source: The Authors 


\section{Extensive case descriptions}

In this section, a reconstruction is presented of how the DDA was transferred to Bangladesh and Vietnam. ${ }^{2}$ In 2008, the Second Delta Committee presented its recommendations for the Netherlands. The Dutch Ministry of Foreign Affairs considered that the approach proposed by this committee could be a model of long-term holistic planning, a model that could be used to aid other delta countries in developing a future-proof strategy. In the past, sharing water expertise to developing countries was linked to development aid. However, Dutch official development assistance budgets were cut and new policies on development cooperation issued by the Dutch government emphasized the shift from aid to aid-and-trade. The idea to spread the DDA to developing countries thus coincided with a shift in thinking about development cooperation. This meant that future collaboration on sharing water expertise (including the DDA) would not only focus on aiding other countries but also on generating business opportunities for the Dutch water sector. See for example Hasan et al. (2019, pp. 6-7) for a more detailed explanation on the link between development cooperation and the DDA in Bangladesh.

In a very schematic way, the transfer works as follows: the Dutch government selects and funds a Dutch consortium, which then formulates a delta plan in close collaboration with (a part of) a ministry in the receiving country. This receiving government ultimately decides whether the delta plan is adapted, i.e., it should be granted any formal status. See Figure 1 for a simplified schematic overview.

Figure 1. Simplified, schematic overview of the actors involved in the transfer process. The actors in the middle, between the two dotted lines, are those directly involved in translating the DDA to the receiving context.

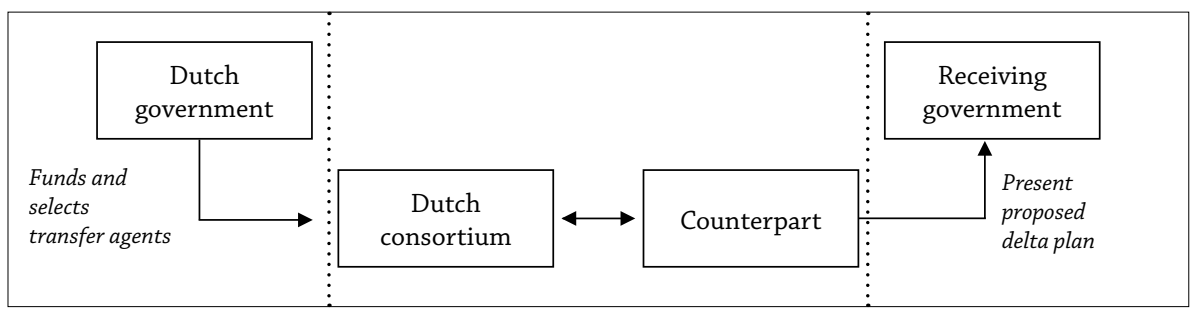

Source: The Authors

\section{Vietnam}

\section{Start}

Dutch governmental actors were looking for ways to re-shape the bilateral relationship as Vietnam was about to become a middle-income country. During a state visit to the Netherlands in 2010, the then Prime Ministers of the Netherlands and Vietnam agreed that both countries would jointly draft a delta plan for the Mekong Delta following the Dutch example. This ambition was established under the Strategic Partnership Agreement on water of the Dutch Ministry of Infrastructure and Environment and the Vietnamese ministries of Agriculture and Rural Development (MARD) and Natural Resources and Environment (MoNRE) (Dutch embassy, 2010).

2 - This article summarizes the delta plans and the process that led to their formulation. Please consult Van Alphen et al. (2021) for a detailed description of the BDP2100 and Hasan et al. (2019) of the MDP. 
This formulation project was funded by the Dutch government and in 2011, a consortium was selected to formulate this Delta Plan for the Vietnamese Mekong delta. The consortium was led by a Dutch engineering firm (Royal Haskoning DHV) and its core partners were consultancy firms (Rebel; Water.nl) and research institutes (Wageningen University and Research; Deltares). The Dutch consortium was teamed up with the Ministry of Agriculture and Rural Development (MARD) and the Ministry of Natural Resources and Environment (MoNRE) to deliver a delta plan by 2013. The Vietnamese government would facilitate the deployment of Vietnamese government officials. In practice, however, MoNRE acted as counterpart to the Dutch and MARD was less involved.

\section{Process}

Water-induced threats such as flooding and saline intrusion affect the Mekong Delta, which covers the southern part of the country. These threats mean that the dominant agricultural practice of growing rice in polders with multiple harvests per year cannot be sustained much longer. In upstream areas, a 'high-dike, triple rice' system is in place. This system has a negative impact on the environment because of its intensive use of fertilizer and pesticides, and because the high-dikes push an excess of flood water to low-lying areas (Tran et al., 2018). In the coastal areas, saline intrusion threatens freshwater agriculture.

Initially, the Dutch government officials and (technical) experts who formed the consortium found it difficult to transfer knowledge. They were expected to work with two different ministries, but there was hardly any collaboration. While historically, most aspects of the Vietnamese water system are covered by MARD, the consortium worked more closely with MoNRE. However, these sectoral ministries lacked the power to introduce integrated plans. In need of a counterpart, the Dutch consortium decided to involve independent Vietnamese experts, i.e., very senior and well-respected bureaucrats and researchers, sometimes referred to as the 'Retired Reformists' (Hasan et al., 2019). Also, the consortium organized stakeholder consultation in the Mekong Delta, following which they adapted ADM to fit the Vietnam context.

Halfway through the process, the Dutch had a draft Mekong Delta Plan that was reviewed by the group of experts. They were extremely critical: although they saw merit in ADM, the ideas were not sufficiently translated to suit the Vietnamese situation. In the second part of the project, the Dutch consortium worked closely with this same group. "We called them the focus group. Next to this, we really tried to become known among other donors, thus the World Bank, Asian Development Bank, IUCN, several NGOs, but also other donor countries." explained respondent 16, a Dutch consortium member.

\section{Adoption}

In 2013 the MDP was formally presented. In the following years, several Mekong Delta Forums were organized. Here, the transferred ideas were discussed by Dutch actors, donor organizations, the 'retired reformists' as well as provincial government officials and central government ministries and the prime minister. In the meantime, international donors actively supported the MDP. The World Bank, together with several donor organizations, organized the Mekong Delta Forums and proposed to use the MDP as a framework for future development works in Vietnam. Shortly after the Mekong Delta Forum of 2017, the Vietnamese government launched Resolution 120 that adopted several key elements of the MDP, including a vision towards 2100, integrating all policy fields for the development of the region. Around the same time, a new Law on Planning was voted, stipulating integrated regional planning. The World Bank is now funding projects in line with the MDP and has funded a new Dutch consortium to develop an integrated planning strategy for the Mekong Delta. 


\section{Bangladesh}

\section{Start}

The Netherlands and Bangladesh were also looking for ways to rejuvenate their bi-lateral relationship. The co-created National Water Management Plan for Bangladesh was never implemented after its launch in 2001 and was therefore considered a failure. To forget about the fiasco, a new successful collaboration in the field of water management was needed and a delta plan seemed able to deliver exactly that. Also, Bangladesh's Prime Minister was personally committed to improving water management in Bangladesh following the Dutch example, meaning a powerful political actor was on board from the beginning. Respondent 79, an employee of the Dutch embassy, illustrates this as follows: "And the formal request [for technical assistance] came from the Prime Minister's office, directly to the embassy. That is a bit unusual [...]. But this one, since the Prime Minister was very much interested, so it directly came from the Prime Minister's office."

From 2014, a Dutch management consultancy firm led a Dutch-Bangladeshi consortium in the formulation process from 2014 to 2016. This consortium was led by a management consultancy firm, Twynstra-Gudde, and worked alongside other consultancy firms (Euroconsult Mott MacDonald; ECORYS), an engineering consultancy firm (Witteveen+Bos) and several research institutes (D.EFAC.TO; Deltares; Wageningen University \& Research; UNESCO-IHE). This consortium involved Bangladeshi consultants and experts as sub-contractors and the deputy team leader was Bangladeshi. Together they formed 'Team A' for the formulation of the Delta Plan. Team A was appointed by the Dutch Embassy in Bangladesh. Also, the General Economic Division (GED) of the Bangladesh Ministry of Planning was involved from the start. They appointed the Policy Research Institute of Bangladesh (PRI) as 'Team B', which was supposed to ensure alignment of the delta plan in the governance system of Bangladesh. We kindly refer the reader to Figure 1 of Hasan et al. (2020, p. 167) for a detailed and clear overview of all actors involved and their relationship to each other in the formulation of the BDP2100.

\section{Process}

Bangladesh is almost entirely covered by the Ganges-Brahmaputra river delta, meaning that almost the whole country is vulnerable for flooding and tropical cyclones. Developing a delta plan was thus associated with sustainable economic development and the country's ambition to become a high-income country by 2040.

As in Vietnam, the transfer agents gathered available information about the country context and organized stakeholder consultations across the country in so-called 'Delta Ateliers'. A major difference was the existence of two teams: a team A which was expected to draft solutions for Bangladesh and a Team B, consisting of high-level Bangladeshi policy advisors who were expected to transform these solutions into policy proposals in line with the practices in Bangladesh.

As the deadline approached, ideas about how to proceed begun to diverge. Team B thus started to write their own version of the delta plan and the GED eventually combined the texts of the two teams in one final document: BDP 2100 - volume 1. In addition to this first strategic document there was a second volume: an investment agenda consisting of 80 projects to be implemented under the BDP 2100. This second volume was written by a third team (Team C), which was funded and coordinated by the World Bank. The GED considered the whole set of documents as "the" Delta Plan and presented both volumes to parliament and to the Prime Minister of Bangladesh. "There are six baseline studies and volume 1 and volume 2 of the delta plan, these are the delta plan." explained respondent 80 , a Bangladeshi civil servant. 


\section{Adoption}

Bangladesh formally adopted the BDP 2100 in September 2018. The World Bank had led the composition of Volume 2 and announced that it would fund projects in line with the Bangladesh Delta Plan 2100. At the same time, the Dutch government was funding a follow-up project in which the same consortium was assisting the Bangladeshi government with capacity building needed for the implementation of the delta plan. As Respondent 73, a government official at GED, explained: "It [...] will go for its implementation through our five-year planning cycle. [...] 80 projects were initially selected to implement, to act on Delta Plan objectives. Those were assessed by World Bank experts. [...] Some of the projects are already approved, approved by the government for implementation. So implementation already began".

\section{Analysis}

\section{Network management strategies}

The network management strategies of the Dutch actors were analyzed based on the framework presented in Table 1. The effect of these strategies is discussed here. As section 4.1 and 4.2 illustrate, we distinguish two parts of the process in Vietnam.

\section{Connecting strategies}

In both cases, connecting strategies were used to organize support and three connected groups of actors particularly stood out. The first group concerned actors with the ability to change the policy course. In both countries, the water ministries were considered "weak" partners for formulating a delta plan as their mandates and political power were limited. "From our experience we thought that the Ministry of Environment or the Ministry of Water Resources is not capable of making such a plan for the whole of Bangladesh, for all sectors. (...) Because they have limited capacities and especially was, and still is, very weakly institutionally developed." (Respondent 65, Bangladeshi consultant). Moreover, in Vietnam, there was a literal and figurative distance between the delta in the south and the water-ministries in Vietnam's capital Hanoi in the north, $1500 \mathrm{~km}$ away from the delta. "So, you know, like somehow we said two parallel trajectories happened: one in Hanoi, one in the delta." (Respondent 96, Vietnamese senior expert). Overall, the initial network composition in Vietnam proved to be inadequate but actors with decision making power were engaged later, such as provincial leaders and the Prime Minister. In Bangladesh, the process involved more powerful actors such as the GED and Prime Minister from the start.

Second, actors with boundary spanning capacities were involved in the transfer process in both cases. These included Dutch embassies who acted as the "linking pin" but also senior Vietnamese and Bangladeshi water experts who had studied in the Netherlands. Respondents believed that a majority of Bangladeshi water experts had studied in the Netherlands. Dutch consultants who had built (informal) relationships with Vietnamese or Bangladeshi actors acted as boundary spanners too: "especially [name Dutch consultant] and the embassy have played an important role, namely by engaging about thirty independent experts in Vietnam" (Respondent 16, Dutch consultant).

Finally, international organizations and other donor countries felt that a vision was needed, a direction for the future on which to base their activities to prevent conflicting or overlapping activities. International donors rallied behind the MDP before the national government did, and in Bangladesh the World Bank was already involved during the formulation of the delta plan. Currently, the World Bank plays a major role in implementing both delta plans. 


\section{Exploring content}

In both cases strategies for exploring content were deployed. Formally both Vietnam and Bangladesh requested support from the Dutch government in reforming their water governance. However, the Dutch government was not passively awaiting interest from abroad but rather took an active approach as the bi-lateral relationship with both Vietnam and Bangladesh needed a new impetus. As such, both delta plans took water as a starting point, but framed the DDA to make it appear like a meaningful response to the critical issues of climate change (Vietnam) and (economic) development (Bangladesh).

Dutch actors furthermore realized that they needed to broaden the policy scope for the delta plans to be policy relevant. Initial support for the MDP declined when the completion deadline approached. "Some people gave support when in a formal meeting with a supportive atmosphere. (...) and when you're alone again this support declines. Then things are suggested and negative reactions trickle down from all sides" (Respondent 16, Dutch consultant). In the second phase, connecting the MDP to the agricultural reforms helped make the MDP a policy-relevant document. In Bangladesh, therefore, the focus of the delta plan was more connected to a relevant policy issue (i.e., economic development) from the start.

\section{Process agreements}

We observed dedicated rules for shaping the formulation process in Bangladesh but not in Vietnam. There the Dutch consortium faced a complex policymaking practice, as Vietnam has a highly complex governance system. Explicit process agreements of who has access to the policy formulation network for the MDP and how decisions should be taken seemed to be absent. As a result, Dutch actors focused on understanding and gaining access to existing policymaking structures in Vietnam, which also proved challenging. The involvement of the independent, senior Vietnamese experts marked a turning point as these experts helped the Dutch actors in playing by the rules of the game: they held strategic knowledge about the Vietnamese institutional context and were in a position to access those with decision-making power.

In both countries, participatory sessions and consultations took place to engage various stakeholders in the process. Additionally, in Bangladesh, NGOs organized a critical conference as they believed participants of these 'Delta Ateliers' were recruited only from the networks of the project consortia and their partners: "We invited government and project officials and to our surprise they actually came and we had a good discussion" (Respondent 76, Bangladeshi NGO). Finally, criticism on process transparency led to the online publication of the draft delta plan and a collection of what authorities referred to as "non-political" comments from the general public.

\section{Arranging}

Finally, organizational and funding arrangements were created to facilitate interaction. At first sight, the formal organization to formulate the delta plans was similar: a partnership between a Dutch consortium and a central government body to draft a delta plan. In addition, there were stakeholder consultations to collect input, a panel of experts to review the (draft) plans and steering committees. A Bangladeshi government official explained it thus: "Actually, we did something from an administrative point of view, like we've created a Steering Committee headed by the Chief secretary of the prime minister's office. [...] So for them to feel comfortable, all the important secretaries participated in that commission." (Respondent 80 , Bangladeshi government official). Still, there were differences. The setup with three teams in Bangladesh had been especially designed to draft policy within existing structures, while the MDP was created largely 
outside existing policy formulation channels and eventually made an impact through the Mekong Delta Forums.

\section{Managed and unmanaged events}

As outlined in section 3, we focused upon deliberate attempts to steer the policy formulation network by Dutch actors. However, we also observed that network management strategies were deployed by other actors. For example, Bangladeshi actors played a leading role in selecting GED as their counterparts in Bangladesh and individual leadership at GED also facilitated the transfer: "He [=senior official at GED] managed to keep all stakeholders on board and had direct access to the prime minister" (Respondent 100, Dutch government official). At times, network management activities by Dutch and non-Dutch actors also reinforced each other. An example of such a sequence occurred when Dutch individuals engaged the 'retired reformists' in Vietnam, who in turn reached out to the Vietnamese leadership to involve them. Alongside the deliberate management activities, windows of opportunities were seized. A Dutch government official described the role of coincidence: "If Sheik Hasina had chosen something other than water, this would never have happened in Bangladesh. (...) If there wouldn't have been people at the embassy willing to try something new, this would not have succeeded. If Cees Veerman had not presented that thing [=advice of Second Delta Committee], this [=MDP] would never have happened." (Respondent 101, Dutch government official).

\section{Network management for effective policy transfer}

The Dutch attempted to connect to certain actors, looked for policy issues to connect to and created ad hoc project organizations. They included people with policy skills or a management or economic perspective alongside water experts and engineers. For example, a former minister who chaired the Dutch Delta Committee formally led the process in Vietnam and, although well-endowed with engineering expertise too, the consortium in Bangladesh was led by a management firm. The interview results show that the Dutch actors in both cases occasionally and deliberately sought to steer the network, but also that the response to these actions differed. Where the Vietnamese actors at first remained largely unresponsive to the Dutch efforts and eventually allowed them to indirectly influence regular policymaking structures, domestic actors in Bangladesh actively reflected on new arrangements to make the project succeed.

In both cases, the transferred ideas were adopted after several translations to match the receiving context, through the approval of the delta plan (Bangladesh) or the incorporation of its core ideas in a resolution (Vietnam). Respondents also believed that they had achieved their goal. They considered it a success that the DDA's long-term planning was introduced in their countries and spoke of a "new way of thinking" triggered by the transfer of Dutch ideas. The role of network management in this adoption became clear from comparing the cases. This management facilitated the extensive translation of the DDA: both delta plans significantly differed from each other and from the Dutch Delta Programme. This is perhaps best illustrated by the different interpretation and use of the scenarios - a key element of the DDA - in Vietnam and Bangladesh. In the Netherlands, scenarios were used to explore potential futures, but in Bangladesh and Vietnam, a single scenario was selected as the desired future to achieve through the delta plan. "There was a phase where the Vietnamese said: 'you have four scenarios in the report, but we only want to go for the scenario we desire.", a Dutch consultant explained (Respondent 16). Moreover, the following description by a Bangladeshi government official is representative of similar statements that were made by multiple respondents in both countries: "It is the Bangladesh Delta Plan, not the Dutch Delta Plan. Since the Dutch are pioneers, world champions in managing water resources, we have taken their knowledge, shared in their experience in preparing this delta 
plan. Maybe we adopted parts of their process, but it has been customized according to the context and needs of the country. This is not a true copy." (Respondent 74, Bangladeshi government official). As such, it seems fair to conclude that the original Dutch ideas were translated to great extent to fit the political, social and institutional context in Vietnam and Bangladesh.

However, the composition of the network as well as the topics it focuses on are changing. New actors such as sectoral ministries and implementing agencies are increasingly taking part in these debates. In both countries, and especially in Bangladesh, the policy debate now concentrates on topics in which the delta plans remain indefinite. For example, the delta plan considers that shifting to flood-based farming is a radical but necessary change in Vietnam, but at the same time high-dike systems and closing off the delta are still on the table for the coastal region. A similar debate is taking place in Bangladesh, where critics point out that some chapters of the BDP advocate for an open delta system while others call for more polders (see e.g. BAPA $\&$ BEN, 2019). The existing network dissolved (Vietnam) or remained largely unaltered (Bangladesh) after the formal adoption of the ideas. Respondents therefore agreed that despite all the results achieved, the hardest part was still to come and would be integrating these visions into strategic planning and investment programs. While this is beyond the scope of this paper, it illustrates the need to update network management strategies during implementation.

\section{Discussion and conclusion}

The aim of this study was to understand how network management strategies, as described in the broader network management literature, are deployed in and affect the dynamics of policy transfer. We thereby sought to bridge two disciplinary traditions and at the same time, move beyond analyses of policy formulation and policy transfer that focus on state actors only (Benson \& Jordan, 2011; Moloney \& Stone, 2019). We used a framework of network management strategies based on network theory; this framework was used to analyze the relationship between the network management strategies deployed and the effectiveness of the transfer process. Based on a comparative case study, we found that such strategies indeed contributed to the adequate policy translation and adoption of the Dutch Delta Approach (DDA) in Bangladesh and Vietnam. Despite similarities - in both cases, similar reasons underpinned the transfer and a similar set-up of project consortia was used -, different network management activities were deployed to tailor the DDA to both countries. Based on this research, four conclusions may be drawn.

First, effective network management contributed to effective policy translation, which in turn facilitated the adoption of the transferred ideas. As outlined in section 5 , we observed network management strategies by the Dutch actors throughout the processes in Bangladesh and Vietnam, which resulted in (1) the formation of a policy formulation network with access to decision making, (2) a plan that connected to policy priorities and (3) the creation of special arrangements which facilitated the formulation and formal adoption of ideas. Overall, exploring content strategies aided the effective translation of the DDA, which would not have been possible without bringing policy relevant actors on board. Network management strategies thus facilitated collaboration and joint image building. However, both delta plans were formulated in governance hybrids (Koffijberg et al., 2012) where hierarchical steering dominates through central government decision making. Adoption was thus also facilitated by hierarchical governance modes whereby measures were introduced through top-down decision making. A closer look reveals that horizontal network governance was predominantly used to facilitate the translation of ideas, while vertical steering facilitated the adoption of the delta plans. This brings us to our key conclusion regarding the relationship between network management, 
policy translation and policy transfer, i.e., that network management strategies primarily contributed to creating a translation that was acceptable for decision makers. We therefore argue that network management is a condition for effective policy transfer.

Second, and related to this, the soft nature of the DDA as a transfer object facilitated joint image building and thus translation. The resulting delta plans transcended the level of a sectoral water management plan and became multi-sectoral visions of a desired future. Although the DDA has both hard and soft elements, the studied delta plans were mainly based on the 'soft' principles, norms and planning ideas (see Stone (2010) on soft transfer objects). The abstract nature of the transferred policy actually facilitated its adoption as the ambiguity of the DDA (as pointed out in section 5.3) helped the delta plans gain a broad support base. All actors could project their own narrative on the DDA and it thus served different interests and different actors (see also Béland \& Cox, 2016; Soremi, 2019). Nevertheless, the transfer of the DDA required active translation and network management by the Dutch senders. This is in line with the notion that soft transfers depend more on translation and on the interaction between agents than on contextual compatibility (Khirfan et al., 2013). We thus conclude that a more abstract transfer object may facilitate adoption, provided that the network is actively managed.

The third conclusion relates to the ability of transfer agents to learn how to use network management strategies for policy transfer. We conclude that the Dutch actors became aware of the need for and impact of certain network management strategies from their experiences in Vietnam and used this lesson to shape the process in Bangladesh. Network management was initially limited in Vietnam, or at least did not have the intended effect. The project setup in Bangladesh deliberately resembled that of the second part of the process in Vietnam. For example, the Dutch actors realized they could work with non-sectoral and more powerful political actors instead of the 'usual suspect' (water ministries), leading to altered connecting strategies. This learning effect supports our previous conclusion on the importance of network management for transfer. Nevertheless, we acknowledge the influence of unmanaged events and network management by non-Dutch actors. For instance, Dutch transfer agents had to find alternative ways to mobilize a supportive coalition in Vietnam, and they lost grip on the process in Bangladesh.

Finally, it is worth mentioning that network management needs to be continued beyond adoption. Several authors previously established that policy transfer does not end when policy proposals are formally adopted or agreed upon (Zhang \& Yu, 2019), and respondents in both cases reported barriers related to implementation. The promotion and ambiguity of the DDA allowed it to become a 'coalition magnet' (Béland \& Cox, 2016) but also impeded consensus on the way forward. Actors previously uninvolved in the process (e.g., water ministries, implementing agencies) have now joined the debate on how to shape this idea in practice. Changing circumstances cause network compositions to change over time (Klijn \& Koppenjan, 2016) and new actors may bring new perspectives to the table or frustrate the implementation of transferred ideas. As such, the networked delta plans ran into the operational and bureaucratic barriers described by McGuire \& Agranoff (2011). Even though the policy formulation process seems to 'tick all boxes', we hypothesize that the actors in the network minimized network management efforts after adoption. The transition from policy formulation to implementation triggered a new policy round (see Klijn \& Koppenjan, 2016), which implied updating the composition, content, rules of the game and participants of the network.

This study has focused on the network management strategies deployed by senders in policy transfer and used this to explain how network management may impact the effectiveness of 
transfer. Although we have included the response of receivers and pointed to the key role of some domestic actors, future research may explicitly concentrate on network management by actors at the receiving end of transfer. Particularly interesting is the following question: to what degree are their network management strategies used to facilitate or resist transfer. In addition, this study has concluded that network management is needed in all phases of decision making: during agenda setting (initiation of policy transfer) and policy formulation but also during implementation. This raises new questions, such as: which changes in the network are required to facilitate implementation? And what does it mean for the process if implementing actors are inactive during formulation? Answers to these questions may also shed light on the relationship between policy formulation and the implementation of transferred policy ideas.

Network management strategies play an important role in policymaking and this study has shown that this not only holds for domestic policymaking in Western countries, but that these strategies are key for policy transfer to highly dissimilar contexts as well. It has shown how effective network management and a rather abstract policy object resulted in policy adoption in the studied cases. This shows how the nature of the process of transfer is partly determined by the nature of the transfer object. This finding is important because policy transfer studies now increasingly focus on soft transfers (Benson \& Jordan, 2011). Soft transfer requires active framing to connect this concept discursively to other issues or practices. To make the transferred concept resonate among receivers, transfer agents should actively deploy network management. By studying policy transfer from a network management perspective, policy transfer researchers and practitioners may be better able to understand how transferring agents create a context of receptivity and understanding for their ideas.

\section{Bibliography}

Alphen, J. van, Heer, J. de, \& Minkman, E. (2021). Strategies for climate change adaptation: lessons learnt from long-term planning in the Netherlands and Bangladesh. Water International, 1-28. https://doi.org/10.1080/02508060.2021.1911069

BAPA, \& BEN.(2019). Resolution of the "Special Conference on Bangladesh DeltaPlan 2100 and Sustainable DevelopmentinBangladesh",117. KhrishibidInstitution,Farm Gate,Dhaka, BangladeshRetrievedfrom: https://www.bapa.org.bd/wp-content/uploads/2020/11/aHR0cDovL2JhcGEub3JnLmJkLnJ3czQubXktaG9zdGluZy1wYW5lbC5jb20vQ29uZmVyZW5jZUNvbGxlY3Rpb24vMTQ4LVNDQkRQX0ZpbmFsX1Jlc29sdXRpb25fQm90aF9pbl9FbmdsaXNoX0JhbmdsYTI4MDEyMDE5LnBkZg.pdf

Bekkers, V., \& Tummers, L. (2018). Innovation in the public sector: Towards an open and collaborative approach. International Review of Administrative Sciences, 84(2), 209-213.

https://doi.org/10.1177/0020852318761797

Béland, D., \& Cox, R. H. (2016). Ideas as coalition magnets: coalition building, policy entrepreneurs, and power relations. Journal of European Public Policy, 23(3), 428-445.

https://doi.org/10.1080/13501763.2015.1115533

Benson, D., \& Jordan, A. (2011). What have we learned from policy transfer research? Dolowitz and Marsh revisited. Political Studies Review, 9(3), 366-378.

https://doi.org/10.1111/j.1478-9302.2011.00240.x 
Büscher, C. H. (2019). Imagineering Waterscapes : The Case of the Dutch Water Sector. Water Alternatives, 12(3), 814-835.

Dolowitz, D., \& Marsh, D. (1996). Who Learns What from Whom: a Review of the Policy Transfer Literature. Political Studies, 21, 343-351.

https://doi.org/10.1111/j.1467-9248.1996.tb00334.x

Dolowitz, D. P. (2017). Transfer and Learning: One Coin Two elements. Novos Estudos. CEBRAP, 36(1), 35-56.

https://doi.org/10.25091/s0101-3300201700010002

Dunlop, C. A. (2017). Policy learning and policy failure: Definitions, dimensions and intersections. Policy \& Politics, 45(1), 3-18. https://doi.org/10.1332/030557316X14824871742750

Dussauge-Laguna, M. I. (2012). The neglected dimension: bringing time back into cross-national policy transfer studies. Policy Studies, 33(6), 567-585.

https://doi.org/10.1080/01442872.2012.728900

Evans, M., \& Barakat, S. (2012). Post-war reconstruction, policy transfer and the World Bank: the case of Afghanistan's National Solidarity Programme. Policy Studies, 33(6), 541-565.

https://doi.org/10.1080/01442872.2012.722293

Evans, M., \& Davies, J. (1999). Understanding Policy Transfer: A multi-level, multi-disciplinary perspective. Public Administration, 77(2), 361-385.

https://doi.org/10.1111/1467-9299.00158

Hasan, S., Evers, J., \& Zwarteveen, M. (2020). The transfer of Dutch Delta Planning expertise to Bangladesh: A process of policy translation. Environmental Science \& Policy, 104, 161-173. https://doi.org/10.1016/j.envsci.2019.11.001

Hasan, S., Evers, J., Zegwaar, A., \& Zwarteveen, M. (2019). Making waves in the Mekong Delta: the work behind the transfer of Dutch Delta Planning expertise. Journal of Environmental Planning and Management, 62(9), 1583-1602.

https://doi.org/10.1080/09640568.2019.1592745

James, O., \& Lodge, M. (2003). The Limitations of "Policy Transfer" and "Lesson Drawing" for Public Policy Research. Political Studies Review, 1(2), 179-193.

https://doi.org/10.1111/1478-9299.t01-1-00003

Johnston, L. (2005). 'Waking Up The Sleeping Giant': Change Management, Policy Transfer and the Search for Collaboration. Public Policy and Administration, 20(3), 69-89.

https://doi.org/10.1177/095207670502000307

Jong, M. de, \& Bao, X. (2007). Transferring the technology, policy, and management concept from the Netherlands to China. Knowledge, Technology, \& Policy, 19(4), 119-136. https://doi.org/10.1007/BF02914894

Khirfan, L., Momani, B., \& Jaffer, Z. (2013). Whose authority? Exporting Canadian urban planning expertise to Jordan and Abu Dhabi. Geoforum, 50, 1-9.

https://doi.org/10.1016/j.geoforum.2013.07.007

Klijn, E. H., \& Koppenjan, J. (2016). Governance Networks in the Public Sector. Abingdon: Routledge. https://doi.org/10.4324/9781315887098

Klijn, E. H., Steijn, B., \& Edelenbos, J. (2010). The Impact Of Network Management On Outcomes In Governance Networks. Public Administration, 88(4), 1063-1082.

https://doi.org/10.1111/j.1467-9299.2010.01826.x 
Koffijberg, J., Bruijn, H. de, \& Priemus, H. (2012). Combining Hierarchical and Network Strategies: Successful Changes in Dutch Social Housing. Public Administration, 90(1), 262-275. https://doi.org/10.1111/j.1467-9299.2011.01974.x

Levi-faur, D. (2005). A Question of Size? A Heuristic for Stepwise Comparative Research Design. In B. Rihoux \& H. Grimm (Eds.), Innovative Comparative Methods for Policy Analysis (pp. 43-66). New York, NY: Springer.

Marsh, D., \& Sharman, J. C. (2009). Policy diffusion and policy transfer. Policy Studies, 30(3), 269288. https://doi.org/10.1080/01442870902863851

Mcguire, M., \& Agranoff, R. (2011). The Limitations of Public Management Networks. Public Administration, 89(2), 265-284.

https://doi.org/10.1111/j.1467-9299.2011.01917.x

Minkman, E., \& van Buuren, A. (2019). Branding in policy translation: How the Dutch Delta approach became an international brand. Environmental Science and Policy, 96. https://doi.org/10.1016/j.envsci.2019.03.005

Moloney, K., \& Stone, D. (2019). Beyond the State: Global Policy and Transnational Administration. International Review of Public Policy, 1(1), 104-118.

https://doi.org/10.4000/irpp.344

Mukhtarov, F., de Jong, M., \& Pierce, R. (2016). Political and ethical aspects in the ethnography of policy translation: Research experiences from Turkey and China. Environment and Planning A: Economy and Space, 49(3)

https://doi.org/10.1177/0308518X16674935

Mukhtarov, Farhad, \& Daniell, K. a. (2016). Transfer, Diffusion, Adaptation, and Translation of Water Policy Models. In K. Conca \& E. Weinthal, The Oxford Handbook of Water Politics and Policy (pp. 1-29). Oxford: Oxford University Press.

https://doi.org/10.1093/oxfordhb/9780199335084.013.30

Peck, J., \& Theodore, N. (2010). Mobilizing policy: Models, methods, and mutations. Geoforum, 41(2), 169-174.

https://doi.org/10.1016/j.geoforum.2010.01.002

Peters, D. T. J. M., Klijn, E. H., Stronks, K., \& Harting, J. (2017). Policy coordination and integration, trust, management and performance in public health-related policy networks: a survey. International Review of Administrative Sciences, 83(1), 200-222.

https://doi.org/10.1177/0020852315585061

Rusu, A., \& Loblova, O. (2019). Failure is an option: epistemic communities and health technology assessment. In C. Walker \& T. Baker (Eds.), Public policy circulation: arenas, agents and actions (pp. 103-121). Edward Elgar Publishing.

Sezen, S. (2011). International versus domestic explanations of administrative reforms: the case of Turkey. International Review of Administrative Sciences, 77(2), 322-346. https://doi. org/10.1177/0020852311399229

Soremi, T. (2019). Storytelling and Policy Transfer: The Case of Disaster Risk Reduction Policy Transfer to West Africa. International Review of Public Policy, 1(2), 194-217.

https://doi.org/10.4000/irpp.485

Sørensen, E., \& Torfing, J. (2005). The democratic anchorage of governance networks. Scandinavian Political Studies, 28(3), 195-218.

https://doi.org/10.1111/j.1467-9477.2005.00129.x 
Stone, D. (2010). Private philanthropy or policy transfer? The transnational norms of the Open Society Institute. Policy \& Politics, 38(2), 269-287.

https://doi.org/10.1332/030557309X458416

Stone, D. (2012). Transfer and translation of policy. Policy Studies, 33(6), 483-499.

https://doi.org/10.1080/01442872.2012.695933

Stone, D. (2016). Understanding the transfer of policy failure: bricolage, experimentalism and translation. Policy \& Politics, 1-16.

https://doi.org/10.1332/030557316X14748914098041

Tran, D. D., Halsema, G. Van, Hellegers, P. J. G. J., Ludwig, F., \& Wyatt, A. (2018). Questioning triple rice intensification on the Vietnamese mekong delta floodplains: An environmental and economic analysis of current land-use trends and alternatives. Journal of Environmental Management, 217, 429-441. https://doi.org/10.1016/j.jenvman.2018.03.116

Vinke-de Kruijf, J. (2013). Transferringwatermanagement knowledge: how actors, interaction and context influence the effectiveness of Dutch-funded projects in Romania (Doctoral thesis). University of Twente. https://doi.org/10.3990/1.9789036535397

Warsen, R., Nederhand, J., Klijn, E. H., Grotenbreg, S., \& Koppenjan, J. (2018). What makes public-private partnerships work? Survey research into the outcomes and the quality of cooperation in PPPs. Public Management Review, 20(8), 1165-1185.

https://doi.org/10.1080/14719037.2018.1428415

Wesselink, A. (2016). Trends in flood risk management in deltas around the world: Are we going 'soft'? International Journal of Water Governance, 3(4), 25-46.

https://doi.org/10.7564/15-IJWG90

Yoo, J., \& Kim, S. E. (2012). Understanding the mixture of governance modes in Korean local governments: an empirical analysis. Public Administration, 90(3), 816-828.

https://doi.org/10.1111/j.1467-9299.2011.02015.x

Zevenbergen, C., Khan, S. A., Alphen, J. van, Terwisscha van Scheltinga, C., \& Veerbeek, W. (2018). Adaptive Delta Management: A comparison between the Netherlands and Bangladesh Delta Plan. The International Journal of River Basin Management, 16(3), 2999-3305.

Zhang, Y., \& Yu, X. (2019). Policy transfer: the case of European Union-China cooperation in public administration reform. International Review of Administrative Sciences, 2699. https://doi.org/10.1177/0020852319841427 


\section{Appendix: Literature review of empirical studies on the cases}

Table A.1 Overview of literature on the Mekong Delta Plan (2013).

\begin{tabular}{|c|c|c|c|}
\hline Authors & Year & Title & Type \\
\hline Laeni et al. & $\begin{array}{l}\text { (under } \\
\text { review) }\end{array}$ & $\begin{array}{l}\text { Going Dutch in the Mekong delta: A framing } \\
\text { perspective on water policy translation }\end{array}$ & Journal article \\
\hline Hasan et al. & (2019) & $\begin{array}{l}\text { Making waves in the Mekong Delta: the work } \\
\text { behind the transfer of Dutch Delta Planning ex- } \\
\text { pertise. }\end{array}$ & Journal article \\
\hline Korbee et al. & (2019) & $\begin{array}{l}\text { Navigating the bureaucracy: an analysis of im- } \\
\text { plementation feasibility for the Mekong Delta } \\
\text { Plan, Vietnam. }\end{array}$ & Journal article \\
\hline Seijger et al. & (2019) & $\begin{array}{l}\text { Do strategic delta plans get implemented? The } \\
\text { case of the Mekong Delta Plan. }\end{array}$ & Journal article \\
\hline Vo et al. & (2019) & $\begin{array}{l}\text { Political agenda-setting for strategic delta plan- } \\
\text { ning in the Mekong Delta: converging or diverg- } \\
\text { ing agendas of policy actors and the Mekong } \\
\text { Delta Plan? }\end{array}$ & Journal article \\
\hline Weger & (2019) & $\begin{array}{l}\text { The Vietnamization of delta management: The } \\
\text { Mekong Delta Plan and politics of translation in } \\
\text { Vietnam. }\end{array}$ & Journal article \\
\hline Van Staveren & $(2017)$ & $\begin{array}{l}\text { Governance of "long term delta planning" in } \\
\text { Bangladesh Vietnam and the Netherlands }\end{array}$ & Dissertation \\
\hline Wesselink et al. & (2016) & $\begin{array}{l}\text { Trends in flood risk management in deltas } \\
\text { around the world: Are we going 'soft'? }\end{array}$ & Journal article \\
\hline Zegwaard & (2016) & Mud: deltas dealing with uncertainties & Dissertation \\
\hline $\begin{array}{l}\text { Zevenbergen } \\
\text { et al. }\end{array}$ & (2013) & $\begin{array}{l}\text { Taming global flood disasters. Lessons learned } \\
\text { from Dutch experience. }\end{array}$ & Journal article \\
\hline
\end{tabular}


Table A.2 Overview of the literature on the Bangladesh Delta Plan 2100 (2016).

\begin{tabular}{|c|c|c|c|}
\hline Authors & Year & Title & Type \\
\hline $\begin{array}{l}\text { Hasan, Evers \& } \\
\text { Zwarteveen }\end{array}$ & (2020) & $\begin{array}{l}\text { Unravelling the transfer of Dutch delta plan- } \\
\text { ning expertise to Bangladesh. Part I: a process } \\
\text { of policy translation. }\end{array}$ & Journal article \\
\hline Seijger et al. & (2018) & $\begin{array}{l}\text { Rethinking sediments, tidal rivers and delta } \\
\text { livelihoods: tidal river management as a stra- } \\
\text { tegic innovation in Bangladesh }\end{array}$ & Journal article \\
\hline Zevenbergen et al. & (2018) & $\begin{array}{l}\text { Adaptive Delta Management: a comparison } \\
\text { between the Netherlands and Bangladesh } \\
\text { Delta Plan }\end{array}$ & Journal article \\
\hline Van Staveren & (2017) & $\begin{array}{l}\text { Governance of "long term delta planning" in } \\
\text { Bangladesh Vietnam and the Netherlands }\end{array}$ & Dissertation \\
\hline Nicholls et al. & $(2016)$ & $\begin{array}{l}\text { Integrated assessment of social and environ- } \\
\text { mental sustainability dynamics in the Gan- } \\
\text { ges-Brahmaputra-Meghna delta, Bangladesh. }\end{array}$ & Journal article \\
\hline Zegwaard & $(2016)$ & Mud: deltas dealing with uncertainties & Dissertation \\
\hline $\begin{array}{l}\text { Van den Berg, } \\
\text { Pelzer \& Slager }\end{array}$ & (2015) & $\begin{array}{l}\text { Conditions for Planning Support Systems - } \\
\text { the case of the Dutch Delta approach in Bang- } \\
\text { ladesh. }\end{array}$ & $\begin{array}{l}\text { Conference pa- } \\
\text { per }\end{array}$ \\
\hline Zevenbergen et al. & (2013) & $\begin{array}{l}\text { Taming global flood disasters. Lessons } \\
\text { learned from Dutch experience. }\end{array}$ & Journal article \\
\hline
\end{tabular}

\section{Reviewed literature}

Berg, H. van den, Pelzer, P., \& Slager, K. (2015). Conditions for Planning Support Systems - the case of the Dutch Delta approach in Bangladesh. International Conference on Computers in Urban Planning and Urban Management, 1-26.

Hasan, S., Evers, J., Zegwaard, A., \& Zwarteveen, M. (2019). Making waves in the Mekong Delta : Recognizing the work and the actors behind the transfer of Dutch delta planning expertise. Journal of Environmental Planning and Management, 62(9), 1583-1602. 
Hasan, S., Evers, J., \& Zwarteveen, M. (2020). The transfer of Dutch Delta Planning expertise to Bangladesh : A process of policy translation. Environmental Science \& Policy, 104, 161-173.

Korbee, D., Nguyen, H. Q., Hermans, L., \& Phi, H. L. (2019). Navigating the bureaucracy : An analysis of implementation feasibility for the Mekong Delta Plan. Vietnam. Journal of Environmental Planning and Management, 62(9), 1545-1561.

Nicholls, R. J., Hutton, C. W., Lázár, A. N., Allan, A., Adger, W. N., Adams, H., \& Salehin, M. (2016). Integrated assessment of social and environmental sustainability dynamics in the Ganges-Brahmaputra-Meghna delta. Bangladesh. Estuarine, Coastal and Shelf Science, 183, 370-381.

Seijger, C., Datta, D. K., Douven, W., Halsema, G., \& Khan, M. F. (2018). Rethinking sediments, tidal rivers and delta livelihoods : Tidal river management as a strategic innovation in Bangladesh. Water Policy, 21(1), 108-126.

Seijger, C., Hoang, V. T. M., Halsema, G., Douven, W., \& Wyatt, A. (2019). Do strategic delta plans get implemented? The case of the Mekong Delta Plan. Regional Environmental Change, 19(4), 1131-1145.

Staveren, M. F. van. (2017). Bringing in the Floods: A comparative study on controlled flooding in the Dutch, Bangladesh and Vietnamese deltas. Wageningen University.

Vo, H. T. M., Halsema, G., Seijger, C., Dang, N. K., Dewulf, A., \& Hellegers, P. (2019). Political agenda-setting for strategic delta planning in the Mekong Delta : Converging or diverging agendas of policy actors and the Mekong Delta Plan? Journal of Environmental Planning and Management, 62(9), 1454-1474.

Weger, J. (2019). The Vietnamization of delta management : The Mekong Delta Plan and politics of translation in Vietnam. Environmental Science \& Policy, 100, 183-188

Wesselink, A. (2016). Trends in flood risk management in deltas around the world: Are we going 'soft'? International Journal of Water Governance, 3(4), 25-46.

Zegwaard, A. (2016). Mud: Deltas dealing with uncertainties. Vrije Universiteit Amsterdam.

Zevenbergen, C., Herk, S., Rijke, J., Kabat, P., Bloemen, P., Ashley, R., \& Veerbeek, W. (2013). Taming global flood disasters. Lessons Learned from Dutch Experience. Natural Hazards, 65(3), 1217-1225.

Zevenbergen, C., Khan, S. A., Alphen, J. van, Scheltinga, C., \& Veerbeek, W. (2018). Adaptive Delta Management : A comparison between the Netherlands and Bangladesh Delta Plan. The International Journal of River Basin Management, 16(3), 2999-305. 